\title{
Fc $\gamma$ receptor Illb polymorphism and use of glucocorticoids at baseline are associated with infusion reactions to infliximab in patients with rheumatoid arthritis
}

\author{
Ayumi Okuyama, ${ }^{1}$ Hayato Nagasawa, ${ }^{1}$ Katsuya Suzuki, ${ }^{1}$ Hideto Kameda, ${ }^{1,2}$ \\ Harumi Kondo, ${ }^{2}$ Kouichi Amano, ${ }^{1}$ Tsutomu Takeuchi ${ }^{1,2}$
}

\begin{abstract}
- Additional data (supplementary figure) are published online only. To view these files please visit the journal online http://ard.bmj. com

${ }^{1}$ Rheumatology/Clinical Immunology, Saitama Medical Center, Saitama Medical University, Saitama, Japan ${ }^{2}$ Department of Internal Medicine, School of Medicine, Keio University, Tokyo, Japan
\end{abstract}

\section{Correspondence to}

Professor Tsutomu Takeuchi, 35 Shinanomachi, Shinjuku-ku, Tokyo 160-8582, Japan; tsutake@z5.keio.jp

Accepted 29 August 2010 Published Online First 27 October 2010

\begin{abstract}
Objective Infusion reaction is a major adverse event in patients with rheumatoid arthritis (RA) treated with infliximab. The possible factors including Fc $\gamma$ receptor (FcyR) polymorphism associated with the development of infusion reactions in patients with $\mathrm{RA}$ receiving infliximab were prospectively examined.
\end{abstract}

Methods 96 patients with RA were enrolled and scheduled to receive infliximab at a dose of $3 \mathrm{mg} / \mathrm{kg}$ at weeks 0,2 and 6 and every 8 weeks thereafter. Genetic polymorphisms for Fc $\gamma R$ were examined in FCGR3A 176FN and FCGR3B NA1/2 alleles by allele-specific PCR analysis.

Results An infusion reaction was observed in 17 patients (18\%) during 52 weeks of treatment with infliximab. The FCGR3B NA1/NA1 genotype was found in $75 \%$ of the patients with infusion reactions and in only $37 \%$ of those without ( $p=0.01)$, whereas the FCGR3A $176 \mathrm{~F} / \mathrm{V}$ genotype was equally distributed in the patients with or without infusion reactions. Glucocorticoids were used in $53 \%$ of the patients who developed an infusion reaction and in $80 \%$ of those without an infusion reaction $(p=0.02)$. A multivariable logistic regression model showed that the FCGR3B NA1/NA1 genotype and use of glucocorticoids at baseline could be used as independent predictive factors for infusion reactions (OR 6.1 (95\% Cl 1.9 to 24.3) and OR 0.26 (95\% Cl 0.08 to 0.84$)$, respectively). The presence of anti-infliximab antibody during infliximab treatment was also associated with infusion reactions.

Conclusion FCGR3B NA1/NA1 genotype, use of glucocorticoids and the presence of anti-infliximab antibody accounted for nearly all patients with RA who developed infusion reactions.

\section{INTRODUCTION}

Biological agents targeting a specific molecule provide an effective means for therapeutic management of rheumatoid arthritis (RA) due to their specificity and powerful functional capabilities, which has resulted in a paradigm shift in the treatment strategy of this disease. ${ }^{1-4}$ Despite their effectiveness, several adverse drug reactions associated with the use of biological agents have been identified, such as opportunistic infections and the development of hypersensitivity/infusion reactions. For example, approximately $10-23 \%$ of patients with RA experience infusion reactions (including fever, malaise, headaches, erythema and urticaria) to infliximab, a chimeric monoclonal IgG1 antibody against tumour necrosis factor $\alpha$ (TNF $\alpha)$, in combination with methotrexate (MTX). ${ }^{5-9}$ Although much less frequent, severe infusion reactions such as anaphylactic/anaphylactoid symptoms are also observed in patients with RA. ${ }^{8}$ Despite the fact that most of these reactions are only mild or moderate in severity, they may lead to discontinuation of treatment, which is of particular concern and highly relevant to daily clinical practice. ${ }^{9}$ It is tempting to speculate that biological agents may induce these reactions in a portion of susceptible patients by causing hypersensitivity to the given biological agents, ${ }^{10}$ in part through the immunogenicity of the agents or by direct effects on cellular functions through the Fc portion of the products. ${ }^{11}$

The Fc portion of IgG-based biological agents can bind to $\mathrm{Fc} \gamma$ receptors $(\mathrm{Fc} \gamma \mathrm{R})$ for clearing the agents and even affecting cellular functions including phagocytosis, antibody-dependent cellular cytotoxicity and neutrophil activation. ${ }^{12}$ Fc $\gamma \mathrm{R}$ consist of three major families which are encoded by eight genes: FCGRIA, FCGRIB, FCGR1C, FCGR2A, FCGR2B, FCGR2C, FCGR3A and FCGR3B. Functional allelic polymorphisms leading to distinct effector capabilities have been identified in the receptors Fc $\gamma$ RIIa, Fc $\gamma$ RIIb, Fc $\gamma$ RIIIa and Fc $\gamma$ RIIIb. ${ }^{12}$

Since the FCGR2A $131 \mathrm{H} / \mathrm{R}$ allele strongly influences the ability of FcyRIIa to bind human IgG2 but has only limited effects on IgG1 and IgG3 binding, ${ }^{12}$ we focused on the FCGR3A 158F/V and FCGR3B NA1/NA2 alleles and prospectively examined the possible association of these FCGR alleles, development of antibody to infliximab and clinical parameters with development of infusion reactions to infliximab in patients with RA.

\section{METHODS}

\section{Patients and treatment}

Consecutive patients with RA who fulfilled the 1987 revised criteria of the American College of Rheumatology for the classification of $\mathrm{RA}^{13}$ and satisfied the Japanese guidelines for the use of anti-TNF biological agents ${ }^{14}$ were invited to participate in the study. Ninety-six patients showing incomplete response to MTX were enrolled after obtaining their written informed consent. The 2008 Declaration of Helsinki and the 2008 Ethical Guidelines for Clinical Research by the Japanese Ministry of Health, Labour and Welfare were online under the BMJ Journals unlocked scheme, see http:// ard.bmj.com/info/unlocked.dtl 
strictly followed in this study. The patients were scheduled to receive infliximab at a dose of $3 \mathrm{mg} / \mathrm{kg}$ at weeks $0,2,6$ and subsequently every 8 weeks added to MTX at the Saitama Medical Center between September 2003 and March 2008. The management of infusion was performed using a previously reported protocol ${ }^{15}$ approved by the University Institutional Review Board. We did not perform any premedication including histamine antagonists, paracetamol and additional glucocorticoids until the first infusion reaction developed in individual patients. Blood samples were taken for genotyping before initiation of infliximab, and anti-infliximab antibody (AIA) was measured at each infusion visit during the 52 -week study.

\section{Assessment of efficacy and safety}

Patients were followed up longitudinally with examinations at baseline and at each regular infusion visit and emergency visit during the 52 -week study. To monitor disease activity and disability, the 28-joint Disease Activity Score based on $\mathrm{C}$ reactive protein (DAS28-CRP) and serum levels of CRP, matrix metalloproteinase-3 (MMP-3) and Health Assessment QuestionnaireDisease Index (HAO-DI) were determined. The attending physicians recorded any adverse drug reactions at baseline, at each regular infusion visit and emergency visit during the 52 -week study period.

\section{Measurement of AIA}

AIA was measured using an ELISA kit (Immunodiagnostik, Bensheim, Germany). Briefly, serum samples were diluted with phosphate buffered saline (PBS) and added to 96-well plastic plates coated with the $\mathrm{F}(\mathrm{ab})_{2}$ portion of infliximab to avoid interference with rheumatoid factor (RF). After incubating overnight at $4^{\circ} \mathrm{C}$, the wells were washed with PBS and horseradish peroxidase-labelled infliximab was added. After incubation for $60 \mathrm{~min}$, the plates were extensively washed with PBS, followed by addition of substrates into each well. The $\mathrm{OD}_{450}-\mathrm{OD}_{620}$ was recorded using an ELISA reader.

\section{Determination of Fc $\gamma \mathbf{R}$ polymorphisms}

Heparinised venous blood was collected from patients and chromosomal DNA was isolated using phenol-chloroform extraction. Genetic polymorphisms for Fc $\gamma \mathrm{R}$ were examined in FCGR3A 176F/V and FCGR3B NA1/2 alleles by allele-specific PCR analysis, as previously described. ${ }^{16} 17$ PCR products were separated on $3 \%$ agarose gels and visualised under ultraviolet light using a photoimager.

\section{Statistical analysis}

Baseline variables of patients with RA were analysed for association with development of infusion reactions using a $\chi^{2}$ test for categorical variables and Student $t$ test for continuous variables. Univariate logistic regression analysis was used to screen for potential predictor variables, and a stepwise selection process was used to generate a multivariate model for potential predictors of infusion reactions. All statistical analyses were performed on a Mac OS X platform (Sun Microsystems, Palo Alto, California, USA) using JMP Version 8.0.2.

\section{RESULTS \\ Clinical characteristics of the patients with RA who developed infusion reactions}

As shown in table 1, the development of infusion reactions, concomitant medications and the continuation of infliximab varied in individual patients. The observed infusion reactions were typically mild or moderate and included chills, fever, erythema and urticaria; however, one patient developed a severe anaphylactoid reaction and hypotension. Prior to the study, this patient had been enrolled in a clinical trial for infliximab, and the severe infusion reaction developed in this study after the second infusion, which represented a 3-year interval since he last received infliximab in the clinical trial. The most common manifestation in the patients was skin eruption $(n=10)$, followed by fever $(n=3)$, nausea/vomiting $(n=3)$ and headache $(n=2)$. Although these manifestations were not considered severe, nearly all of

Table 1 Demographic and clinical characteristics of patients with infusion reactions

\begin{tabular}{|c|c|c|c|c|c|c|c|c|c|c|c|c|c|c|}
\hline No & Gender & $\begin{array}{l}\text { Age } \\
\text { (year) }\end{array}$ & $\begin{array}{l}\text { Duration } \\
\text { (month) }\end{array}$ & $\begin{array}{l}\text { DAS28 at } \\
\text { baseline }\end{array}$ & $\begin{array}{l}\text { CRP } \\
\text { (mg/dl) }\end{array}$ & $\begin{array}{l}\text { RF } \\
\text { (IU/ml) }\end{array}$ & ANA $(x)$ & $\begin{array}{l}\text { MMP-3 } \\
\text { (ng/ml) }\end{array}$ & HAQ-DI & $\begin{array}{l}\text { Clinical } \\
\text { manifestation }\end{array}$ & $\begin{array}{l}\text { Time of } \\
\text { infusion } \\
\text { reaction } \\
\text { (weeks) }\end{array}$ & $\begin{array}{l}\text { MTX } \\
\text { (mg/week) }\end{array}$ & $\begin{array}{l}\text { PRED } \\
\text { (mg/day) }\end{array}$ & $\begin{array}{l}\text { Adherence } \\
\text { to infliximab }\end{array}$ \\
\hline 1 & $\mathrm{~F}$ & 51 & 60 & 6.9 & 7.8 & 12 & 160 & 346 & 2.6 & Chills, fever, dyspnoea & 38 & 13 & 0 & Discontinue \\
\hline 2 & $\mathrm{~F}$ & 52 & 9 & 6.6 & 6.9 & 444 & 0 & 188 & 2.1 & $\begin{array}{l}\text { Hot flushes, headache, } \\
\text { subfever }\end{array}$ & 1 & 8 & 10 & Continue \\
\hline 3 & M & 69 & 624 & 5.7 & 3.9 & 191 & 80 & 180 & 1.8 & $\begin{array}{l}\text { Anaphylactoid reaction, } \\
\text { hypotension }\end{array}$ & $\begin{array}{l}2 \text { (after } \\
\text { 3-year } \\
\text { interval) }\end{array}$ & 6 & 5 & Discontinue \\
\hline 4 & $\mathrm{~F}$ & 40 & 50 & 4.8 & 2.9 & 864 & 80 & 200 & 1.3 & Urticaria & 14 & 12.5 & 0 & Discontinue \\
\hline 5 & $\mathrm{~F}$ & 50 & 97 & 3.5 & 0.3 & 23 & 80 & 121 & 0.3 & Urticaria & 30 & 10.5 & 5 & Discontinue \\
\hline 6 & $\mathrm{~F}$ & 68 & 48 & 4.5 & 3.2 & 42 & 80 & 95 & 0.13 & Erythema & 14 & 8 & 0 & Discontinue \\
\hline 7 & M & 65 & 240 & 4.8 & 2.8 & 1080 & 320 & 85 & 2.6 & $\begin{array}{l}\text { Hot flushes, headache, } \\
\text { nausea }\end{array}$ & 14 & 10 & 3 & Discontinue \\
\hline 8 & $\mathrm{~F}$ & 52 & 255 & 5.7 & 3.3 & 845 & 160 & 191 & 1.3 & Erythema & 30 & 8 & 0 & Discontinue \\
\hline 9 & $\mathrm{~F}$ & 31 & 29 & 4.8 & 0.1 & 17 & 1280 & 98 & 0.5 & Nausea & 44 & 8 & 0 & Discontinue \\
\hline 10 & $\mathrm{~F}$ & 60 & 210 & 4.2 & 1.8 & 250 & 80 & 359 & 0.6 & Urticaria & 14 & 8 & 0 & Discontinue \\
\hline 11 & $\mathrm{~F}$ & 52 & 168 & 3.5 & 0.3 & 15 & 1280 & 121 & 0.3 & Urticaria & 2 & 6 & 0 & Discontinue \\
\hline 12 & $\mathrm{~F}$ & 57 & 360 & 6.6 & 6.4 & 98 & 1280 & 360 & 1.5 & Erythema & 14 & 6 & 4 & Discontinue \\
\hline 13 & $\mathrm{~F}$ & 33 & 21 & 6.6 & 5.2 & 122 & 80 & 612 & 1.1 & Erythema & 14 & 10 & 4 & Continue \\
\hline 14 & $\mathrm{~F}$ & 37 & 9 & 7.5 & 5.6 & $<5$ & 0 & 280 & 1.9 & Fever & 14 & 6 & 10 & Discontinue \\
\hline 15 & $\mathrm{~F}$ & 37 & 60 & 4.3 & 1.4 & 446 & 80 & ND & 0.8 & Erythema & 30 & 8 & 0 & Continue \\
\hline 16 & $\mathrm{~F}$ & 63 & 4 & 7.4 & 11.0 & 1060 & 80 & 412 & 2.5 & Nausea, vomiting & 14 & 8 & 7.5 & Discontinue \\
\hline 17 & $\mathrm{~F}$ & 64 & 134 & 6.0 & 0.8 & $<5$ & 1280 & 253 & 1.9 & Erythema & 22 & 6 & 0 & Discontinue \\
\hline
\end{tabular}

ANA, antinuclear antibody; CRP, C reactive protein; DAS28, 28-joint Disease Activity Score; HAQ-DI, Health Assessment Questionnaire-Disease Index; MMP, matrix metalloproteinase;

MTX, methotrexate; ND, not done; PRED, prednisolone; RF, rheumatoid factor. 
the patients (15 of 17) discontinued infliximab due to the development of these infusion reactions.

\section{Demographics and clinical characteristics of the patients}

As shown in table 2, the mean age of the patients was 54 years and $83 \%$ were women. The mean disease duration was 8 years, RF positivity was $90 \%$, the mean DAS28 score was 5.2 and the mean serum HAQ-DI level was 1.5, suggesting that the patients with RA enrolled in this study were established, active and disabled.

There were no significant differences in the demographics and clinical characteristics between patients who developed infusion reactions and those who did not, with the exception of the concomitant use of glucocorticoids. Glucocorticoids were used in $53 \%$ of patients with infusion reactions compared with $80 \%$ of patients without infusion reactions. In contrast, no significant differences in the demographics and clinical characteristics between patients who continued infliximab and those who discontinued its use were demonstrated in this study.

\section{Fc $\gamma R$ polymorphism}

Allele distributions in the patients with RA for the FCGR3A $176 \mathrm{~F} / \mathrm{V}$ and FCGR3B NA1/NA2 polymorphisms are summarised in table 3 . In this cohort of patients, the distribution of the FCGR3A high-affinity genotype V/V was $6 \%$ whereas the $\mathrm{V} / \mathrm{F}$ and $\mathrm{F} / \mathrm{F}$ genotypes were observed with a frequency of $48 \%$ and $46 \%$, respectively. The occurrence of the V/V genotype was slightly lower than in the healthy Japanese population (8.6\%). ${ }^{18}$ The V/V genotype was enriched in patients with RA with infusion reactions $(12 \%)$ over those without such reactions $(5 \%)$, but the difference was not significant. The distributions of the genotypes for the FCGR3A 176F/V allele between patients with and without adherence to infliximab were comparable.

The high-affinity genotype of FCGR3B (NA1/NA1) was the most prevalent genotype in the patients with RA (44\%), while the NA1/NA2 and NA2/NA2 genotypes were found in 33\% and $23 \%$ of patients, respectively. The FCGR3B NA1/NA1 genotype was found in $70 \%$ of patients with infusion reactions but was present in only $37 \%$ of patients without infusion reactions, indicating that this genotype is associated with the development of infusion reactions. In contrast, the low-affinity genotypes NA1/NA2 and NA2/NA2 were only observed in 18\% and
$6 \%$, respectively, of patients who developed infusion reactions, which is much lower than the $37 \%$ and $27 \%$, respectively, of those without reactions. Analyses confirmed that the distribution of the FCGR3B genotypes between patients with and without infusion reactions was significantly different $(\mathrm{p}=0.01)$. On the other hand, such differences in distribution of the FCGR3B genotypes were not observed between those with and without adherence to infliximab.

The presence of AIA during each visit was found to be positive in $19 \%$ of the patients. The development of AIA was significantly higher in patients with infusion reactions than in those without $(65 \%$ and $9 \%$, respectively, $p<0.001)$, whereas no difference was observed in patients with or without adherence to infliximab ( $15 \%$ and $22 \%$, respectively, $p=0.40)$.

\section{Potential predictive variables for infusion reactions}

The impact of the presence or absence of risk factors identified on the development of infusion reactions is summarised and compared in figure 1 . In order to create a multivariate model of potential predictors of infusion reactions, we first screened a series of baseline variables which included age, gender, duration of RA, DAS score, levels of CRP, MMP-3, HAQ-DI, RF and antinuclear antibody, doses of MTX and prednisolone equivalent, glucocorticoid use and FCGR3A V/V+V/F and FCGR3B NA1/ NA1 genotypes by univariate logistic regression. As shown in table 4, the FCGR3B NA1/NA1 genotype and use of glucocorticoids were significant predictive variables, consistent with the above analyses. Even by stepwise selection, these variables were identified as significant factors associated with infusion reactions (data not shown).

We next subjected these two variables to multivariate logistic regression analyses which allowed for differences in patients with or without infusion reactions to be adjusted. From these analyses, the FCGR3B NA1/NA1 genotype and use of glucocorticoids were finally identified as significant independent variables associated with the development of infusion reactions. The ORs of the FCGR3B NA1/NA1 genotype and the use of glucocorticoids were 6.1 (95\% CI 1.9 to $24.3, \mathrm{p}=0.002)$ and 0.26 ( $95 \%$ CI 0.08 to $0.84, \mathrm{p}=0.025$ ), respectively (table 5 ).

Finally, we examined the potential additive effect of the three identified factors on the development of infusion reactions. Patients with RA with only one factor had a rate of infusion

Table 2 Patient characteristics and infliximab-related outcome

\begin{tabular}{|c|c|c|c|c|c|c|c|}
\hline \multirow[b]{2}{*}{ Subject } & \multirow[b]{2}{*}{ Total $(n=96)$} & \multicolumn{2}{|c|}{ Infusion reaction during 52 weeks } & \multirow[b]{2}{*}{ p Value } & \multicolumn{2}{|c|}{ Adherence to infliximab during 52 weeks } & \multirow[b]{2}{*}{ p Value } \\
\hline & & Yes $(n=17)$ & No $(n=79)$ & & Continued $(n=46)$ & Discontinued $(n=50)$ & \\
\hline Age (years) & $54 \pm 13$ & $52 \pm 12$ & $55 \pm 13$ & 0.82 & $56 \pm 12$ & $53 \pm 14$ & 0.16 \\
\hline Female (\%) & 83 & 88 & 81 & 0.55 & 89 & 78 & 0.14 \\
\hline Disease duration (years) & $8 \pm 9$ & $11 \pm 14$ & $8 \pm 8$ & 0.18 & $8 \pm 7$ & $9 \pm 10$ & 0.57 \\
\hline RF positivity (\%) & 90 & 88 & 90 & 0.84 & 91 & 88 & 0.60 \\
\hline $\mathrm{RF}(\mathrm{IU} / \mathrm{ml})$ & $213 \pm 321$ & $324 \pm 394$ & $189 \pm 300$ & 0.10 & $190 \pm 319$ & $145 \pm 324$ & 0.79 \\
\hline ANA positivity (\%) & 32 & 41 & 30 & 0.39 & 30 & 34 & 0.71 \\
\hline ANA titre $(\times)$ & $273 \pm 616$ & $377 \pm 150$ & $251 \pm 69$ & 0.20 & $341 \pm 813$ & $211 \pm 346$ & 0.16 \\
\hline Stage I+II (\%) & 44 & 47 & 43 & 0.46 & 33 & 43 & 0.05 \\
\hline Class $1+2(\%)$ & 65 & 82 & 62 & 0.18 & 65 & 64 & 0.53 \\
\hline DAS28 & $5.2 \pm 1.3$ & $5.4 \pm 1.6$ & $5.2 \pm 1.3$ & 0.69 & $5.1 \pm 1.5$ & $5.4 \pm 1.2$ & 0.22 \\
\hline $\mathrm{CRP}(\mathrm{mg} / \mathrm{dl})$ & $4.0 \pm 3.3$ & $4.1 \pm 3.0$ & $3.9 \pm 3.4$ & 0.87 & $3.5 \pm 3.4$ & $4.3 \pm 3.2$ & 0.26 \\
\hline MMP-3 (ng/ml) & $293 \pm 287$ & $146 \pm 38$ & $301 \pm 309$ & 0.36 & $340 \pm 374$ & $255 \pm 189$ & 0.17 \\
\hline HAQ-DI & $1.5 \pm 0.8$ & $1.4 \pm 0.9$ & $1.5 \pm 0.7$ & 0.76 & $1.5 \pm 0.8$ & $1.5 \pm 0.7$ & 0.96 \\
\hline MTX dose (mg/week) & $8 \pm 3$ & $8 \pm 2$ & $8 \pm 3$ & 0.35 & $8 \pm 4$ & $9 \pm 3$ & 0.95 \\
\hline Use of glucocorticoids (\%) & 75 & 53 & 80 & $0.02^{*}$ & 74 & 76 & 0.81 \\
\hline Glucocorticoid dose (mg/day) & $4 \pm 3$ & $3 \pm 4$ & $5 \pm 3$ & 0.92 & $5 \pm 4$ & $4 \pm 3$ & 0.19 \\
\hline
\end{tabular}


Table 3 Association of Fc $\gamma$ receptor polymorphism and anti-infliximab antibody (AIA) with infliximab-related outcome

\begin{tabular}{|c|c|c|c|c|c|c|c|}
\hline \multirow[b]{2}{*}{ Subject } & \multirow[b]{2}{*}{$\begin{array}{l}\text { Total } \\
(n=96)\end{array}$} & \multicolumn{2}{|c|}{$\begin{array}{l}\text { Infusion reaction during } \\
52 \text { weeks }\end{array}$} & \multirow[b]{2}{*}{ p Value } & \multicolumn{2}{|c|}{$\begin{array}{l}\text { Adherence to infliximab during } \\
52 \text { weeks }\end{array}$} & \multirow[b]{2}{*}{ p Value } \\
\hline & & $\begin{array}{l}\text { Yes } \\
(n=17)\end{array}$ & $\begin{array}{l}\text { No } \\
(n=79)\end{array}$ & & $\begin{array}{l}\text { Continued } \\
(n=46)\end{array}$ & $\begin{array}{l}\text { Discontinued } \\
(\mathrm{n}=50)\end{array}$ & \\
\hline \multicolumn{8}{|c|}{ FCGR3A 176F/V } \\
\hline$F / F$ & $44(46)$ & $7(41)$ & $37(47)$ & 0.58 & $22(48)$ & $22(44)$ & 0.53 \\
\hline $\mathrm{F} / \mathrm{N}$ & $46(48)$ & $8(47)$ & $38(48)$ & & $20(44)$ & $26(52)$ & \\
\hline $\mathrm{V} / \mathrm{V}$ & $6(6)$ & $2(12)$ & $4(5)$ & & $4(9)$ & $2(4)$ & \\
\hline \multicolumn{8}{|c|}{ FCGR3B NA1/NA2 } \\
\hline NA1/NA1 & 42 (44) & $13(77)$ & $29(37)$ & $0.01^{*}$ & $16(35)$ & $26(52)$ & 0.23 \\
\hline NA1/NA2 & $32(33)$ & $3(18)$ & $29(37)$ & & $18(39)$ & $14(28)$ & \\
\hline NA2/NA2 & $22(23)$ & $1(6)$ & $21(27)$ & & $12(26)$ & $10(20)$ & \\
\hline \multicolumn{8}{|l|}{ AlA } \\
\hline$(+)$ & $18(19)$ & $11(65)$ & 7 (9) & $<0.01^{*}$ & $7(15)$ & $11(22)$ & 0.40 \\
\hline$(-1)$ & $78(81)$ & $6(35)$ & $72(91)$ & & $39(85)$ & $39(78)$ & \\
\hline
\end{tabular}

Values are numbers (\%) unless otherwise indicated.

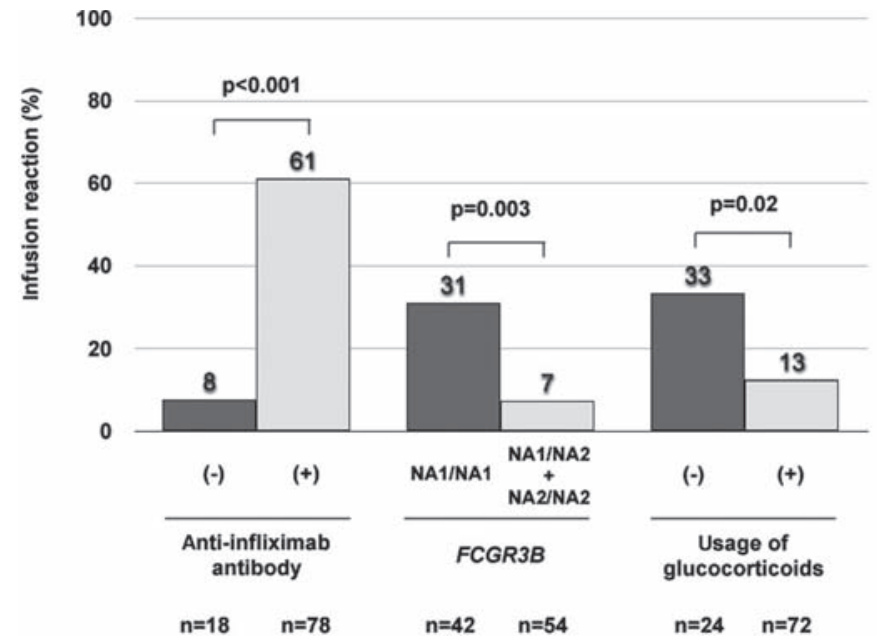

Figure 1 Percentage of patients with rheumatoid arthritis who developed an infusion reaction during the 52-week study in those with or without anti-infliximab antibody, those with or without FCGR3B NA1/NA1 genotype and those with or without concomitant use of glucocorticoids.

Table 4 Univariate logistic regression analysis for potential predictors of infusion reaction

\begin{tabular}{lcllr}
\hline Variables & Estimates & SE & OR & p Value \\
\hline Age (years) & -0.02 & 0.02 & 0.98 & 0.37 \\
Gender (female vs male) & 0.24 & 0.40 & 1.62 & 0.55 \\
Duration (years) & 0.04 & 0.03 & 1.04 & 0.12 \\
DAS28 & 0.08 & 0.21 & 1.08 & 0.69 \\
CRP (mg/dl) & 0.01 & 0.08 & 1.01 & 0.87 \\
MMP-3 (per 10 ng/ml) & -0.01 & 0.01 & 0.99 & 0.55 \\
HAQ-DI & -0.12 & 0.39 & 0.89 & 0.75 \\
RF (per 10 IU/ml) & 0.01 & 0.00 & 1.00 & 0.14 \\
ANA (×) & 0.00 & 0.00 & 1.00 & 0.46 \\
MTX (mg/week) & 0.03 & 0.09 & 1.03 & 0.77 \\
MTX duration (months) & 0.00 & 0.01 & 1.00 & 0.72 \\
Use of glucocorticoids & -0.63 & 0.28 & 0.53 & $0.03^{*}$ \\
Dose of prednisolone (mg/day) & -0.13 & 0.09 & 0.88 & 0.14 \\
FCGR3A V/N+V/F vs F/F & 0.11 & 0.27 & 1.12 & 0.67 \\
FCGR3B NA1/1 vs NA1/2+2/2 & 0.86 & 0.31 & 2.37 & $<0.01^{*}$ \\
\hline ANA antinuclar antibody; CRP C reactive proten; DAS28, $28-j 017$ Disease Activiy
\end{tabular}

ANA, antinuclear antibody; CRP, C reactive protein; DAS28, 28-joint Disease Activity Score; HAO-DI, Health Assessment Questionnaire-Disease Index; MMP, matrix metalloproteinase; MTX, methotrexate; RF, rheumatoid factor. reactions of $11 \%$, whereas those with two or three factors had rates of $53 \%$ and $100 \%$, respectively (see figure in online supplement), demonstrating that these three factors additively account for the infusion reactions to infliximab observed in the 96 patients with RA examined in this study.

\section{DISCUSSION}

The results of this study show that the high-affinity FCGR3B NA1/NA1 genotype and the absence of glucocorticoid use at baseline are the main independent predictive factors for the development of infusion reactions to infliximab in Japanese patients with RA. This study is the first to demonstrate a role for the FCGR3B NA1/NA1 genotype in infusion reactions to infliximab.

Mild to moderate and severe infusion reactions were observed in $18 \%$ and $1 \%$, respectively, of the Japanese patients with RA treated with infliximab during the 52 -week course of this study. This result is consistent with previous studies showing that the incidence of infusion reactions to infliximab was approximately $10-23 \%$ of patients with RA per year. ${ }^{5-7} 815$ The most frequent manifestations of the infusion reactions observed in this study were consistent with those reported for infusion reactions to infliximab in clinical practice settings in both the USA ${ }^{5}$ and Japan. ${ }^{8}$ A significant proportion of these patients subsequently discontinued infusion, implying that infusion reactions may account, as well as lack of efficacy, for the low retention rate of infliximab observed in the first year of treatment, ${ }^{919-21}$ while others do not. ${ }^{22} 23$ The inconsistency of the retention rate for infliximab among studies may result from the variable management strategies used to reduce infusion reactions, which include premedication, ${ }^{5}$ gradual increases in infusion speed, ${ }^{7}$ adjustment of infusion intervals ${ }^{24}$ and dose increments, ${ }^{25}$ among others.

It has been shown using radiolabelled infliximab in patients with RA that the formation of infliximab and anti-infliximab complexes were found in non-responders, one of which showed an anaphylactoid reaction, resulting in higher liver/spleen uptake and rapid clearance of infliximab. ${ }^{11}$ It was recently observed that the IgE class of AIA is associated with the development of severe infusion reactions, ${ }^{26}$ whereas true IgE-mediated hypersensitivity is not related to acute infusion reactions in most cases. ${ }^{27}$ This possibility in one patient who developed an anaphylactoid reaction in this cohort remains to be addressed. 
Table 5 Multivariate model of predictors of infusion reaction by logistic regression

\begin{tabular}{lcllr}
\hline & Estimates & OR & 95\% Cl & p Value \\
\hline FCGR3B NA1/1: NA2/2+NA1/2 & 0.90 & 6.1 & 1.9 to 24.3 & $<0.01$ \\
Glucocorticoid use & -0.68 & 0.26 & 0.08 to 0.84 & 0.03 \\
\hline
\end{tabular}

We found that $19 \%$ of the patients with RA developed AIA during the 52-week study period. The reported prevalence of AIA in patients with RA varies from $12 \%$ to $44 \%$ and appears to be inversely proportional to the serum levels of infliximab and therapeutic response. ${ }^{28}$ The dose of MTX did not significantly affect the development of AIA in our study (data not shown). In this study, infusion reactions frequently occurred between 14 and 30 weeks after initiating infliximab. Since the infusion interval was increased to 8 weeks after induction at 0,2 and 6 weeks, the serum trough levels of infliximab probably lowered at the infusions with 8-week intervals, supporting the above observation in this study. However, the precise mechanisms related to AIA and the development of infusion reactions are not fully understood and require further study.

Numerous studies have analysed the possible association between FCGR2A and FCGR3A polymorphisms and the efficacy of biological agents against TNF $\alpha$ in patients with RA. ${ }^{29-31}$ However, the association between these polymorphisms and the adverse effects of anti-TNF $\alpha$ has not been fully explored. In this regard, the FCGR3B NA2 allele has been shown to be associated with urinary tract infections in patients with RA treated with MTX or etanercept. ${ }^{32}$ Fc $\gamma$ RIIIb is expressed exclusively on neutrophils, eosinophils ${ }^{12}$ and basophils. ${ }^{33}$ The isoform containing the FCGR3B NA1 allele produces larger phagocytic, oxidative burst and degranulation responses than the FCGR3B NA2 allele. ${ }^{32}$ Thus, the FCGR3B NA1/NA1 genotype with high affinity to Ig present on the surface of neutrophils, eosinophils and basophils may account for the higher incidence of infusion reactions to infliximab. In addition, optimal ligand concentrations leading to formation of immune complexes may allow binding to FcyRIIIb and subsequent activation of cells. ${ }^{34}$ Recently, variation in the copy number of FCGR3B has been shown to be associated with susceptibility to systemic autoimmunity. ${ }^{35}$ Copy number variation of FCGR3B may play a role in infusion reactions and warrants further examination.

One may speculate that glucocorticoids may interfere with the binding, activation and effector function of immune cells, thereby reducing the severity and frequency of infusion reactions. Some of these effects may be shared with MTX. In this study, the concomitant use of oral glucocorticoids was significantly associated with a reduced risk of developing an infusion reaction, consistent with recent reports. ${ }^{9} 36$ Therefore, not only the moderate- to high-dose glucocorticoids given as a premedication, but also the low-dose daily glucocorticoids may be a potent inhibitor of infusion reactions. Fc $\gamma$ RIIIb is a phosphatidyl inositol-linked cell surface protein and thus lacks any self-kinase activity. Instead, Fc $\gamma R$ IIa is coupled with Fc $\gamma$ RIIIb to transduce signals. As one of the functional polymorphisms in FcyRIIa is the $131 \mathrm{H}$ allele which confers receptor affinity to IgG2 subclass, it is unlikely that this receptor plays a direct role in binding to the IgG1 monoclonal antibody infliximab. Nevertheless, the possibility that other polymorphisms of FCGR2A associated with receptor function contribute to infusion reactions should be examined.

There are a number of limitations that warrant mention. First, the number of patients examined in this study was insufficient to demonstrate an association between $F C G R 3 A$ polymorphism and infusion reactions. Second, in addition to the small number of patients, other aspects of the study design also imposed limitations. For example, the study was designed to monitor infusion reactions during 52 weeks, meaning that infusion reactions appearing after 52 weeks could not be addressed. Third, this was an open-label study which may have affected the incidence and severity of infusion reactions and the response and retention rates. However, the incidence and the types of infusion reactions in this study were comparable to those of previous reports, as were the other results related to the efficacy and retention rate of infliximab. ${ }^{37} 38$ Also, AIA is typically developed during the treatment period and this information would not be available before starting infliximab; it is apparent that the presence of AIA is limited in its use as a predictive marker. When the two risk factors excluding AIA are used as predictive variables, they were still associated with approximately $40 \%$ of infusion reactions observed in this study (data not shown).

In summary, we have shown that the FCGR3B NA1/NA1 genotype and the absence of glucocorticoid usage are predictive factors of infusion reactions in patients with RA. Premedication for infliximab may therefore not be necessary for all patients but only for those with the FCGR3B NA1/NA1 genotype without daily glucocorticoids.

Acknowledgements The authors thank all medical staff of Saitama Medical University and Keio University.

Funding Part of this study was supported by a Research Grant-In-Aid for Scientific Research by the Ministry of Health, Labour and Welfare of Japan.

Competing interests None of authors are industry employees. TT has received consultant fees from Mitsubishi-Tanabe Pharma, Bristol-Myers-Squibb and Novartis, and lecture fees from Mitsubishi-Tanabe Pharma, Takeda Pharmaceutical, Abbott, Eisai Pharma and Chugai Pharma. HK received honoraria from Mitsubishi-Tanabe Pharma, Centocor, Wyeth Japan, Takeda Pharmaceutical, Abbott, Eisai Pharma and Chugai Pharma.

\section{Patient consent Obtained.}

Ethics approval This study was conducted with the approval of the internal review board of Saitama Medical University.

Provenance and peer review Not commissioned; externally peer reviewed.

\section{REFERENCES}

1. Scheinecker C, Redlich K, Smolen JS. Cytokines as therapeutic targets: advances and limitations. Immunity 2008;28:440-4.

2. Saag KG, Teng GG, Patkar NM, et al. American College of Rheumatology 2008 recommendations for the use of nonbiologic and biologic disease-modifying antirheumatic drugs in rheumatoid arthritis. Arthritis Rheum 2008;59:762-84.

3. van der Kooij SM, le Cessie S, Goekoop-Ruiterman YP, et al. Clinical and radiological efficacy of initial vs delayed treatment with infliximab plus methotrexate in patients with early rheumatoid arthritis. Ann Rheum Dis 2009;68:1153-8.

4. Nam JL, Winthrop KL, van Vollenhoven RF, et al. Current evidence for the management of rheumatoid arthritis with biological disease-modifying antirheumatic drugs: a systematic literature review informing the EULAR recommendations for the management of RA. Ann Rheum Dis 2010;69:976-86.

5. Wasserman MJ, Weber DA, Guthrie JA, et al. Infusion-related reactions to infliximab in patients with rheumatoid arthritis in a clinical practice setting: relationship to dose, antihistamine pretreatment, and infusion number. J Rheumatol 2004;31:1912-17.

6. Kapetanovic MC, Larsson L, Truedsson L, et al. Predictors of infusion reactions during infliximab treatment in patients with arthritis. Arthritis Res Ther 2006;8:R131.

7. Lequerré $\mathbf{T}$, Vittecoq 0 , Klemmer $\mathrm{N}$, et al. Management of infusion reactions to infliximab in patients with rheumatoid arthritis or spondyloarthritis: experience from an immunotherapy unit of rheumatology. J Rheumatol 2006;33:1307-14.

8. Takeuchi T, Tatsuki Y, Nogami Y, et al. Postmarketing surveillance of the safety profile of infliximab in 5000 Japanese patients with rheumatoid arthritis. Ann Rheum Dis 2008;67:189-94

9. Du Pan SM, Dehler S, Ciurea A, et al. Comparison of drug retention rates and causes of drug discontinuation between anti-tumor necrosis factor agents in rheumatoid arthritis. Arthritis Rheum 2009;61:560-8.

10. Radstake TR, Svenson M, Eijsbouts AM, et al. Formation of antibodies against infliximab and adalimumab strongly correlates with functional drug levels and clinical responses in rheumatoid arthritis. Ann Rheum Dis 2009;68:1739-45. 
11. van der Laken $\mathbf{C J}$, Voskuyl $A E$, Roos $J C$, et al. Imaging and serum analysis of immune complex formation of radiolabelled infliximab and anti-infliximab in responders and non-responders to therapy for rheumatoid arthritis. Ann Rheum Dis 2007;66:253-6

12. Hogarth PM. Fc receptors are major mediators of antibody based inflammation in autoimmunity. Curr Opin Immunol 2002;14:798-802.

13. Arnett FC, Edworthy SM, Bloch DA, et al. The American Rheumatism Association 1987 revised criteria for the classification of rheumatoid arthritis. Arthritis Rheum 1988; 31:315-24.

14. Koike R, Takeuchi T, Eguchi K, et al. Update on the Japanese guidelines for the use of infliximab and etanercept in rheumatoid arthritis. Mod Rheumatol 2007;17:451-8.

15. Cheifetz A, Smedley M, Martin S, et al. The incidence and management of infusion reactions to infliximab: a large center experience. Am J Gastroenterol 2003;98:1315-24.

16. Edberg JC, Langefeld CD, Wu J, et al. Genetic linkage and association of Fcgamma receptor IIIA (CD16A) on chromosome 1q23 with human systemic lupus erythematosus. Arthritis Rheum 2002;46:2132-40.

17. Magnusson V, Johanneson B, Lima G, et al. Both risk alleles for FcgammaRIIA and FcgammaRIIIA are susceptibility factors for SLE: a unifying hypothesis. Genes Immun 2004;5:130-7.

18. Kyogoku C, Tsuchiya N, Matsuta K, et al. Studies on the association of Fc gamma receptor IIA, IIB, IIIA and IIIB polymorphisms with rheumatoid arthritis in the Japanese: evidence for a genetic interaction between HLA-DRB1 and FCGR3A. Genes Immun 2002;3:488-93.

19. Hyrich KL, Lunt $\mathrm{M}$, Watson $\mathrm{KD}$, et al. Outcomes after switching from one anti-tumor necrosis factor alpha agent to a second anti-tumor necrosis factor alpha agent in patients with rheumatoid arthritis: results from a large UK national cohort study. Arthritis Rheum 2007:56:13-20.

20. Buch $\mathbf{M H}$, Bingham SJ, Bryer D, et al. Long-term infliximab treatment in rheumatoid arthritis: subsequent outcome of initial responders. Rheumatology 2007:46:1153-6.

21. Kievit W, Adang EM, Fransen J, et al. The effectiveness and medication costs of three anti-tumour necrosis factor alpha agents in the treatment of rheumatoid arthritis from prospective clinical practice data. Ann Rheum Dis 2008;67:1229-34.

22. Geborek P, Crnkic M, Petersson IF, et al. Etanercept, infliximab, and leflunomide in established rheumatoid arthritis: clinical experience using a structured follow up programme in southern Sweden. Ann Rheum Dis 2002;61:793-8.

23. Zink A, Listing J, Kary S, et al. Treatment continuation in patients receiving biological agents or conventional DMARD therapy. Ann Rheum Dis 2005;64:1274-9.

24. Haraoui B, Cameron $\mathrm{L}$, Ouellet $\mathrm{M}$, et al. Anti-infliximab antibodies in patients with rheumatoid arthritis who require higher doses of infliximab to achieve or maintain a clinical response. J Rheumatol 2006:33:31-6.
25. Finckh A, Simard JF, Gabay C, et al. Evidence for differential acquired drug resistance to anti-tumour necrosis factor agents in rheumatoid arthritis. Ann Rheum Dis 2006;65:746-52.

26. Vultaggio A, Matucci A, Nencini F, et al. Anti-infliximab lgE and non-lgE antibodies and induction of infusion-related severe anaphylactic reactions. Allergy 2010;65:657-61.

27. Cheifetz A, Mayer L. Monoclonal antibodies, immunogenicity, and associated infusion reactions. Mt Sinai J Med 2005;72:250-6.

28. Emi Aikawa N, de Carvalho JF, Artur Almeida Silva C, et al. Immunogenicity of antiTNF-alpha agents in autoimmune diseases. Clin Rev Allergy Immunol 2010;38:82-9.

29. Tutuncu Z, Kavanaugh A, Zvaifler N, et al. Fcgamma receptor type IIIA polymorphisms influence treatment outcomes in patients with inflammatory arthritis treated with tumor necrosis factor alpha-blocking agents. Arthritis Rheum 2005;52:2693-6.

30. Kastbom A, Bratt J, Ernestam S, et al. Fcgamma receptor type IIIA genotype and response to tumor necrosis factor alpha-blocking agents in patients with rheumatoid arthritis. Arthritis Rheum 2007;56:448-52.

31. Tsukahara S, Ikari K, Sato $\mathrm{E}$, et al. A polymorphism in the gene encoding the Fcgamma IIIA receptor is a possible genetic marker to predict the primary response to infliximab in Japanese patients with rheumatoid arthritis. Ann Rheum Dis 2008;67:1791-2.

32. Hughes LB, Criswell LA, Beasley TM, et al. Genetic risk factors for infection in patients with early rheumatoid arthritis. Genes Immun 2004:5:641-7.

33. Meknache N, Jönsson F, Laurent J, et al. Human basophils express the glycosylphosphatidylinositol-anchored low-affinity lgG receptor FcgammaRIIIB (CD16B). J Immunol 2009;182:2542-50.

34. Arora T, Padaki R, Liu L, et al. Differences in binding and effector functions between classes of TNF antagonists. Cytokine 2009;45:124-31.

35. Fanciulli $\mathbf{M}$, Norsworthy PJ, Petretto E, et al. FCGR3B copy number variation is associated with susceptibility to systemic, but not organ-specific, autoimmunity. Nat Genet 2007;39:721-3.

36. Augustsson J, Eksborg S, Ernestam S, et al. Low-dose glucocorticoid therapy decreases risk for treatment-limiting infusion reaction to infliximab in patients with rheumatoid arthritis. Ann Rheum Dis 2007:66:1462-6.

37. Tanaka Y, Takeuchi T, Inoue E, et al. Retrospective clinical study on the notable efficacy and related factors of infliximab therapy in a rheumatoid arthritis management group in Japan: one-year clinical outcomes (RECONFIRM-2). Mod Rheumatol 2008;18:146-52.

38. Nagasawa H, Kameda H, Sekiguchi N, et al. Normalisation of physical function by infliximab in patients with RA: factors associated with normal physical function. Clin Exp Rheumatol 2010:28:365-72. 